\title{
Minding the Gap: Reconciling Human and Technical Perspectives on the IoT for Healthy Ageing
}

\author{
Alessandro Soro, Aloha Hufana Ambe, and Margot Brereton \\ Queensland University of Technology (QUT), 2 George St., 4000 Brisbane, QLD, Australia \\ Correspondence should be addressed to Alessandro Soro; alessandro.soro@qut.edu.au
}

Received 23 June 2017; Revised 25 September 2017; Accepted 8 October 2017; Published 12 November 2017

Academic Editor: Luigi Patrono

Copyright (C) 2017 Alessandro Soro et al. This is an open access article distributed under the Creative Commons Attribution License, which permits unrestricted use, distribution, and reproduction in any medium, provided the original work is properly cited.

\begin{abstract}
There are two distinct bodies of literature on the Internet of Things, one that derives from a technical perspective, while the other comes from a human perspective. From a technical perspective, sensors can automatically detect physical activity, thus enabling elderly people to live independently, while sensors in essence check that they are active, remind them to take their pills, and so on. From a human perspective, people seek control over their lives, good health, social connection, and a sense of well-being that comes from having purpose and feeling competent in daily routines. So are technologies meant to enable users to stay in control of their lives and manage their relations and preferred routines, or do they undermine it, making elderly people feel subjects of surveillance and incompetent, disrupting their daily arrangements? And is there a middle path that we might take in design that creates innovative technologies that are aesthetic in form and function and empowering to use? In this paper, we offer a framework and examples of designs that bridge these perspectives.
\end{abstract}

\section{Introduction}

As the world population grows and gets older, ageing well becomes not just an individual goal, but a broader social and economic concern. In this context, across several research disciplines, scholars are investigating what contribution technology may give for ageing well. This aim can be approached from many different perspectives, but in this paper we mainly focus on two. One perspective identifies the potential health issues that begin to manifest themselves as the bodies age, people become more frail and less active, memory declines, and so on. One alternative perspective looks at the agency of older people and how they deal with a phase in life involving specific changes in habits, capacity, and social connection.

One key way to investigate these matters is through the places and the objects that people inhabit and use. These things embody the arrangements that people make to manage their own experience of ageing, sometimes even representing invaluable aspects of the older person social connections and identity [1-3] and in this age of ubiquitous sensing and connectivity can become the link between the ageing well and the technologies that can enable it [4].

This paper offers a reflection on current research on the Internet of Things, on both technical and social aspects. We carried out a research framework that highlights important but currently less explored issues of agency, reciprocity, and engagement, in addition to the relatively better explored technical issues, such as sensing, activity recognition, and connectivity.

The earliest visions of the Internet of Things (IoT) were founded in supply chain monitoring, making "things" able to identify themselves and their position in the supply chain, for example, using RFID tagging [5]. More recently this vision merged to, and extended, the ubiquitous computing (UbiComp) and ambient assisted living body of research, in which "things" are capable of sensing their surroundings, can process and aggregate this information, and possibly act on it. These "smart objects" can take many forms, from personal fitness trackers to home surveillance devices. Ideally, they allow their users to collect data about their own behavior, what is going on at their home or office, and even the behavior and whereabouts of their loved ones, enabling them to reflect or act on such information or to delegate the decision about a proper course of action to a supporting service.

In this broad context, one key application of the IoT is to support healthy ageing. This could in principle entail a number of opportunities for older people, from supporting 
continuing and meaningful relations, opportunities in the workplace, involvement in the broader community life, and overall ensuring a lifestyle as rewarding and satisfactory as possible. In practice, an overwhelming proportion of projects are focused on physiological health, preventing (or dealing with) physical decline and disease, ensuring safety in the home, and alerting the caregivers if something is wrong. This approach has the clear advantage of offering feasible solutions to well-defined problems, and this thread of research is having a tremendous impact on the field and is effectively transferring to real world products and services.

However, as we will illustrate in this paper, the concentration of most research efforts on supporting independent living against (or in spite of) mental and physical decline, risks legitimizing (and to an extent, even promoting) a stereotyped vision of the experience of ageing, one that sees the older persons as in constant need of care and attention, unable to care for themselves, and therefore a burden to society. At the same time, healthy ageing and safety for the older people are often conceptualized as primary needs that in many ways preempt other personal aspirations, including agency, self-sufficiency, privacy, and dignity.

We argue that a constrained vision of ageing and older users is in fact limiting the scope of IoT research for older people, and that as a research community we are missing tremendous opportunities to create new and more engaging tools and services. We will also show that, by fostering social engagement and reciprocal care, building on self-fulfillment and individual values, and supporting personal routines and family rituals, IoT research can expand its scope to support a healthy lifestyle and at the same time avoid the stigma that is often associated with assistive technologies.

\section{Reproblematizing the Internet of Things}

In this section, we first trace a historical background of IoT research. We discuss how a technology centered vision, focused on needs more than on values and aspiration, risks delineating aging exclusively as a problem to solve, rather than as one stage of life that technology can help to enjoy. By saying that many IoT visions and applications have been conceptualized from a technology-driven perspective, we do not seek to criticize this approach that is legitimate and very effective. We argue however that the IoT can do more than solving problems and in doing so it can take a different perspective on problematic assumptions about ageing, care, privacy, and so on. To better clarify these positions, we will offer one example of IoT technology for older users that takes a human-centered perspective of enhancing users' values and ambitions.

2.1. The Internet of Things. The idea behind smart environments capable of merging the physical and digital world can be traced back at least to the work of Mark Weiser and John Seely Brown and colleagues at Xerox PARC [8]. In their ubiquitous computing vision $[9,10]$, every person has access to countless computing devices that are embedded in the existing infrastructure in such a pervasive way that they become eventually invisible (from attention, if not from sight) and taken for granted.

These devices are able to some degree to anticipate users' needs or preferences, respond to natural interaction modalities, and merge the physical and digital world by injecting computing capabilities into ordinary objects (see the early scenario described in [11]).

In the three decades following its initial publication, the UbiComp vision has inspired many different research initiatives, the most influential being probably the tangible user interfaces [12, 13], ambient intelligence and ambient assisted living [14], context aware computing [15], and wearable computing $[16,17]$.

The Internet of Things (IoT) $[5,7,18]$ can in many respects be considered the latest incarnation of these visions, as it brings together aspects of intelligent sensing of the environment [19], tangible interaction with "smart objects" [20], wearable and mobile applications [21], and applications to smart homes and smart cities [22].

Approaching the IoT from different points of view, these works have understandably drawn different pictures of what the IoT is, could be, or could do. Ashton [5] traces back the concept of the IoT to a presentation at Procter and Gamble where he suggested the idea of products able to speak for themselves and computers able to gather such information using sensors and contactless identification. One early and very influential definition from Atzori and colleagues [7] places the IoT at the intersection of three "visions," respectively, focused on Internet, things, and semantics. Here the IoT is described as a computing paradigm made possible by "a variety of things or objects [...] able to interact with each other and cooperate with their neighbors to reach common goals" [7].

The great impact of Atzori et al.s framework is representative at the same time of the interest that surrounds the IoT and of the effectiveness of the framework to deconstruct and position IoT research efforts from a technological perspective [23]. This framework, however, represents the IoT efforts as largely technology-driven and the IoT related visions as rather technocentric, which on the one hand reflects the current focus of much IoT research (see, e.g., [18, 24]).

Within the IoT domain, applications aimed at supporting older users and healthy ageing represent a major research avenue and have attracted considerable attention. However, as in much research about technologies for older people the way these services and tools are conceptualized in the literature offers a representation of the experience of ageing largely based on negative aspects [25] and leading to a stereotyped vision of mental and physical decline, constant need for assistance, loneliness, and ineptitude with technology. The goals of research and design, in turn, become constrained to a paradigm of "assisting," "supporting," and "filling the gap."

This paragraph and the next draw quotes from the most influential (350+ citations) papers from a Google scholar query on "Internet of Things and elderly." This is clearly not a comprehensive review, nor an attempt to criticize the approach taken in these papers. Rather, we aim to show that one particular problematization of the experience of ageing is disproportionately visible in the literature, compared to 


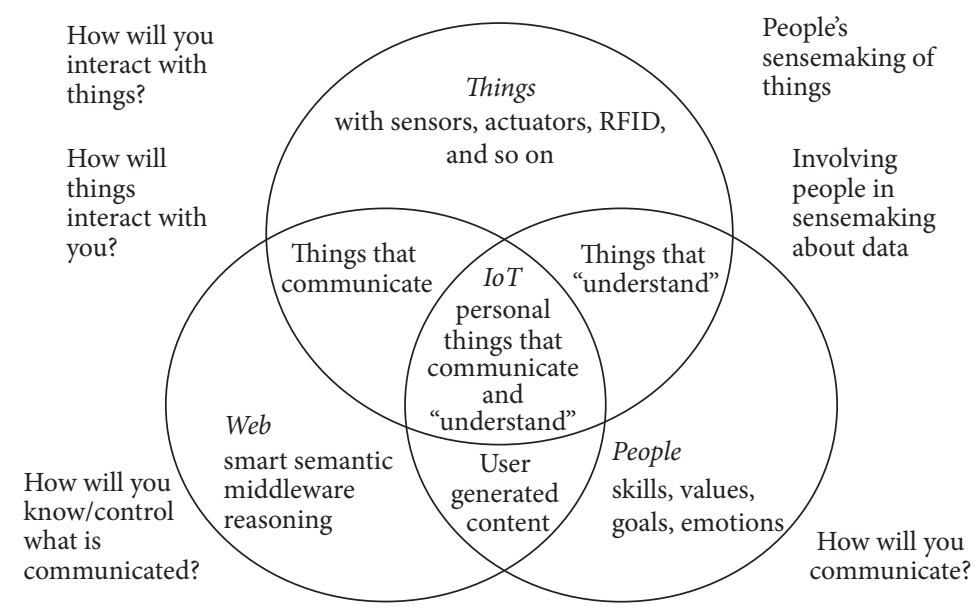

FIgURE 1: The diagram above from [6] is a modified version of Atzori et al.s IoT [7]. Atzori et al's IoT consisted of the triad of things, web connectivity, and semantic reasoning. Soro et al's framework [6] replaced semantic reasoning with people. A human-computer interaction critique notes that, in the end, it will always be people to make sense of data and interpret things and their displays, even if things can communicate and reason with each other. Thus, semantic reasoning is subsumed under "things," and "people" take their place in the triad. This emphasizes the fact that the IoT is used by people and the human-machine interface cannot be ignored in its conceptualization.

other more positive visions. In the literature, the IoT has thus been described as a paradigm for "many different domains, such as home automation, industrial automation, medical aids, mobile healthcare, and elderly assistance" [26], with scenarios that include "ambient assisted living aimed at unobtrusively supporting elderly people in their everyday lives" [20]. Within this context, services for older people have been proposed to allow "the doctor to monitor patients and the elderly in their homes" [18]; to "increase the quality of life and security of the elderly and their families and caregivers" [27]; and to "improve medical conditions of the elderly and keep them safe" [28].

At the same time, the challenges to face in order to make this vision come through are largely described as technical and infrastructural, involving the design and development of proper algorithms, protocols for secure data exchange, data analytics and visualization modalities, energy efficient boards, and standards and best practices to deal with the volume and peculiar nature of IoT data (c.f. [18]). When the humans' perspective is considered, it is largely to acknowledge the difficulties of modelling human behavior so as to sense, anticipate, and adapt to users' preferences, recognize potentially dangerous situations, or respond to human input (see, e.g., [28]).

This focus on technology and "solutions" and the absence of people (other than as generic "users") from most IoT scenarios has drawn some critique, especially (understandably) from the human-computer interaction (HCI) community $[6,23,29,30]$. For example, Koreshoff and colleagues [23] revisited Atzori et al.s IoT framework from a human centric perspective and highlighted some key HCI concerns that were missing from the original framework, such as people sense-making of data, implications for the design of communicating objects, and people's sense-making of things. Soro and colleagues [6] further built on these topics by suggesting to explicitly bring the people into the framework, in place of the "semantics." People, they suggest, give meaning to things and data through their own skills, values, goals, and emotions (see Figure 1).

2.2. The Messaging Kettle. The Messaging Kettle [31] is an IoT device that allows dispersed families to communicate across time-zones over the familiar routine of boiling the kettle to make tea. Modern lifestyle and the job market force many people to live away from their families of origin, often in different countries or continents. Communication across time differences can be problematic: the routines never match, when one party has some spare time for a phone call the other is busy at work or sleeping.

The Messaging Kettle augments an ordinary kettle: a Kettle Mate (in Figure 2, the device sitting on the left of the kettle) includes a heat sensor to detect when the kettle is being used, a voice recorder to record and send simple voice messages, and speakers to play the messages received. A Smart Teabox (in Figure 2, in front of the kettle) includes a touch screen with pen input and the computing and networking logic, where the users can scribble simple handwritten messages.

The Messaging Kettle allows adult children and their older parents to remain in daily touch. A couple of identical devices are deployed, one at each home. When in one home the kettle is being boiled to make tea, the Kettle Mate at the remote location will glow for a period of time, to make this simple routine visible in spite of the geographical distance.

When a voice message is received from the other party a button on the Kettle Mate will light up and will stay on until the message is played. When a scribble is received, it is displayed on the screen that is always on. There is no addressing and no contacts list. The two Messaging Kettles are linked to one another as in a presidential hotline. There is no buzzer or alarms or ringtones, only a warm glow on the Kettle Mate when tea is being made on the other end of the line. 


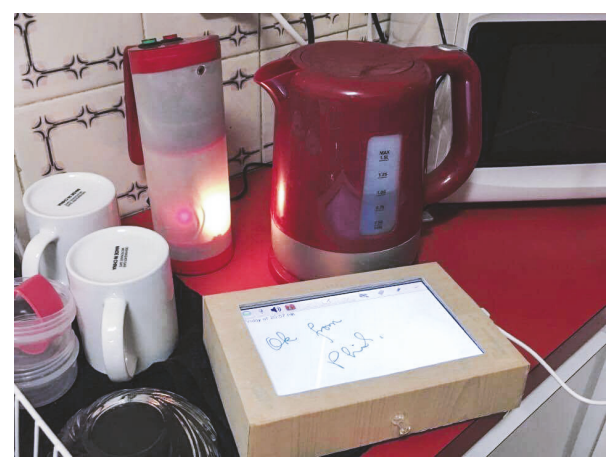

Figure 2: The Messaging Kettle consists in a companion device that augments an ordinary kettle with messaging, scribbling, and virtual presence. When the user turns the kettle on to boil water for a tea, a heat sensor placed on the Kettle Mate (left) reveals the activity. This is shared with an analogous device located at a different home, so that the routine of boiling the kettle becomes visible over distance. The users can also exchange voice messages and scribbles using the Smart Teabox (front).

The Messaging Kettle is located in the design space of IoT technologies for positive ageing [32] and its primary goal is to create a sense of virtual presence by making visible the daily routine of making tea, therefore letting its users know that life on the other side is going on as usual. It can certainly be considered a monitoring device as it includes sensors that, although indirectly, reveal the activity of the user. However, compared to devices that monitor more intimate routines, such as sleeping patterns, the Messaging Kettles insists on a routine that the people involved love to share and used to share when living together in the past.

We point out several aspects of the Messaging Kettle that can serve as examples of the arguments exposed in this paper.

The particular form of monitoring implemented by the Messaging Kettle is reciprocal and symmetrical. Each party gets to see when there is some activity around the kettle at the other end of the line. When people live in the same home they get to see each other's routines. The Messaging Kettle is intended to create a sense of presence that, although different from real family contact, is consistent with the social norms of cohabitation.

The Messaging Kettle allows for asymmetries in the desire to communicate. People have different preference and different lifestyles. Sending a voice message in the middle of the night (when it is early morning at the other end) may be problematic, but a scribble can be a silent a quick way of saying: "thinking of you." Users may have hearing or sight problems, making one form of communication better than the other for them when receiving a message, but at the same time they may have different preferences for sending.

The Messaging Kettle makes routines visible but is respectful of the personal borders. It is built around existing routines and leverages them to implement a reciprocal and noninvasive form of monitoring. It does so without relying on complex models of human behavior. Instead, it relies on the attachment that people often show to their habits and things. For this reason, it does not replace the existing kettle with an augmented one. The kettle (rather than the person) is the target of the sensor, and this is at once respectful of people's arrangements and empowering of people's agency. If one of the parties wants to enjoy a cup of tea "in private" they do not have to switch off the whole device, it is enough to turn away the heat sensor, and this operation is performed manipulating the physical objects, rather than configuring a menu.

Finally, the Messaging Kettle supports communication over daily mundane topics, encouraging both parties to share a little thought every day, rather that forcing them to plan for longer and demanding phone calls. Social engagement is one of the fundamental conditions for healthy aging. It is also the best form of monitoring, as it involves people watching over and caring for one another, in this case with the mediation of the IoT.

With the example of the Messaging Kettle, we wanted to introduce themes of agency, routines, and reciprocity that are often left marginal in IoT research. These themes, we propose, should take a more central role in the design of IoT technologies for healthy ageing: things (whether "smart" or traditional) are embedded in routines and personal arrangements; social relations are founded on reciprocity and engagement; personal values, such as privacy, self-sufficiency, and agency, underpin the sense of dignity in later life. These themes and the reason why they matter will be further developed in the next section.

\section{Related Research}

While ageing is an objective and quantifiable phenomenon, the precise beginning of old age is a subjective experience that varies culturally and historically; thus, old age is considered as a social construct that represents transformations in a period of time encompassing biological and psychological changes [33]. This socially constructed meaning of old age can involve roles assigned to older people, loss of roles accompanied by physical decline, or lessened capacity to actively contribute to society [34]. Historically (and still today in traditionally oral cultures) "old age" was a synonym with experience and wisdom and old people were given high regards and respect in societies [35]. Elders are the custodian of their culture's knowledge as they ensure that history and traditions are passed on to the next generation.

The development of the printing press [35] and the industrial revolution [36] are believed to be major factors which led to the change of attitudes towards ageing and older people. In the advent of the printing press, history and traditions could be passed on to the next generation through books and other printed media [35]. The industrial revolution changed the structure of family and community that progressively became dispersed and mobile as they looked for livelihood [36]. Factory jobs demanded long hours and hard labor and were more suited to younger and stronger workforce. Branco and Williamson note that these changes contributed to the association of negative connotations to old age: a burden and noncontributing.

As discussed by Nelson [37], society has now a tendency to consider older adults as less important, incapable especially to live independently. Ageism is the social perception of 
the stereotypes and prejudices that people have on others based on their age [37]. The changes brought by ageing, such as challenges with social isolation, the difficulties of a frail body, unclear social role, may impede the hope for autonomy, engagement, and an active lifestyle [2]. Such stereotypical negative notion of ageing [37] influences how older adults are seen and in turn leads older people to doubt their selfworth. Isolation and disengagement may then result when older people's roles in society decrease resulting in reduced interaction with others [38], responsibilities and power are taken away, and dignity is lost [39].

More recently, a discourse on active ageing is aiming at reshaping the conversation around what it means to age well, from a deficit-focused one, to a more positive view that highlights agency and connections [40]. In this line of research, Nassir and colleagues proposed a review of factors that influence positive ageing and how to incorporate them in design [32]. Their framework takes up the structure in three pillars from World Health Organization's active ageing [41] and spells out some main determinants underpinning health, participation, and security, offering opportunities for design.

We embrace the positive ageing framework [32] as a conceptual lens to guide our discussion of related works. However, given our focus, we will concentrate on those elements of existing designs that, by giving prominence to supporting health, potentially risk becoming detrimental of the equally important elements of security and participation. Below we review and discuss relevant works evidencing these risks, beginning with how technologies for older users have been largely designed to make life easier or safer, but not necessarily more interesting. These works also show that many technologies are designed to collect, store, and process data about their users' activities, but do not offer proper interfaces to allow them to review, filter, or make sense of this data, resulting in a sense of loss privacy and control over one's own life. This becomes particularly evident when the older adult is made the subject of unidirectional monitoring, sometimes with the effect of disrupting the routines and habits through which people manage their everyday and therefore, paradoxically, working against independence in the attempt to support it.

3.1. Technologies for Older Users. The negative stereotypical notion of old people as frail, unhealthy, sedentary, and uninterested does not apply to everyone [42]. In fact a large proportion of older adults do not consider themselves "old" and live autonomously [43, 44] and enjoy meaningful engagement with their families and their broader community [45]. Durick and colleagues reaffirm that older age does not necessarily entail being stagnant, isolated, a problem for society, and unhealthy or being incapable to learn new technology [25].

However, studies on ageing process and technology showed that there is a close relationship between quality of life and technology usage [46]. Specifically, studies showed that digital technology and the digital world raise issue of exclusion that may negatively affect the quality of life of older adults by becoming isolated in the continuous advancement of such technology [47].
Nevertheless, many designs are focused on assistance, rather than on inclusion, and are often tailored in the assumption that older people are incapable of managing their mental, emotional, social, and physical state [42]. Technologies specifically developed for older people to assist their independent living or to provide "care" are often referred to as gerontechnology [42]. These technologies manage cognitive decline (e.g., pill reminder, wandering tracker) and support or track physical activity (e.g., scooter, walker, fall detector, and emergency systems) or the general well-being (e.g., telecare system, social media applications, social robots, and tracking and monitoring devices) of older people.

Telecare systems and other forms of remote monitoring are criticized as they provide a form of care without human touch or social intimacy and thus may reinforce social isolation [48, 49], but even those technologies that aim to automate and simplify different aspects of everyday life can ultimately result in disrupted routines, dependency on automation, and ultimately further isolation [50]. Routines and the effort of doing the day to day activity can actually result in health benefits to older people, as they generate familiarity, comfort, physical activity, socialisation, and a sense of accomplishment [50].

3.2. Collecting and Interpreting Data. There is value in the data, especially regarding people with high risk situations, such as dementia or serious chronic conditions, and sensorenhanced homes promise empowerment for independent older adults and peace of mind to family members. But how much of a person's well-being can be represented as raw data of their activities, whereabouts, and physiological measures?

The assumption that the data produced by IoT applications could be easily (or even semiautomatically) interpreted and acted upon turns out to be a problematic one [51]. Knowing the data and reflecting upon it may not be enough. For example, studying energy monitoring sensors in the home by Rogers [52] acknowledges the challenge on representing data in these types of systems, especially the ones that are aimed at engaging users. The data's accessibility, intelligibility, usefulness in different forms, devices, or environment is crucial for users to enrich their own experience. How can these data be represented so they become meaningful and in turn empower the user?

Fischer et al. [51] noted that the legibility of the sensor data is dependent on situated reasoning and that its sense is unconditionally bound with situated action, routines, and practices. Also, they assert that sensor data's factual status cannot be confirmed separately from the circumstance of its occurrence.

Not only an understanding of the everyday of the users is necessary to sketch a complete picture, but even in the specific of a given event, the situated nature of the interpretation of sensor data makes it very difficult if not impossible to separate action from context and reduces them to a computable abstraction. As argued by Dourish [53], context, when seen as a property of interaction, is a dynamic and emergent feature that is only relevant to one particular instance of action. Here contextuality is seen as a relation that binds activities to one 
another, rather than as a predictable backdrop against which events take place.

There's a need to look further into the subtlety and nuances of how routines and interactions are managed [54], how mundane arrangements are enacted [2], and how communities of practice are comprised [43] in seeking to design for independence, agency, and engagement. Considering the themes above could lead to successful design strategies to create IoT technologies that support the ageing population [4]. Our goal is to create designs that mesh with the use and practices that surround existing objects and to look at routines and personal arrangements for clues of what novel designs may be accepted.

3.3. Privacy and Control. One critical aspect of introducing monitoring and automation in the lives of older adults is the perceived intrusion in their privacy and the lack of control over one's personal information. Ironically, while technology for older people is designed to assist and support them, the literature shows that these systems strip away from users a degree of control and power.

When the health declines, older adults become more willing to use assistive technologies that involve sharing of data with third parties [55]. In this case, however, they also want to be involved in the choice of system and to be in control over the technology, and control over the system is an important factor in technology acceptance [56]. This involves getting an understanding of the system's usefulness, availability of data, and cost [55]. When it comes to privacy, older adults are very thoughtful and want to be empowered and to retain the sense of the home as a haven with respect for their autonomy [55].

On the contrary, examples of smart technologies and services that endanger their users' personal information are abundant in the research literature and in the news. Smart thermostats, fitness trackers, and smart appliances are easily breached, literally opening the front door to those who possess the skills to hack these systems $[57,58]$. News regarding the violation of online services appears on a regular basis.

In a private setting as a home, the installation of technology especially assistive technology that may monitor people's habits and activities takes away control from older users in a territory they call their own. Crucially, these problems can be somewhat mitigated by improved security and authentication, but a key limitation depends on the inherent asymmetry in the design of many such devices.

This asymmetry can be observed in the direction of the flow of data, from the monitored and assisted to the caregivers, in the opacity, at least from the point of view of the older user, of the algorithms that process this information, and ultimately in the relations of power existing between older people and their adult children, caregivers, and the institutions.

3.4. Asymmetry of Technology and Relations. Older people's care network of family, friends, and health care providers would want to ensure their older loved ones are safe, healthy, and active [59-61]. Adult children are mainly concerned with the well-being and safety of their parents, whereas for the older adult, a key concern is their autonomy, including the autonomy to choose technology to one's own taste [62]. Notions of reciprocity and asymmetry (e.g., affection or interaction between parent-child) and autonomy and role renegotiation (e.g., provider to receiver of support) underpin the older adult's self-worth by allowing them to actively participate and contribute to the family [44].

Technology has the potential to enhance the lifestyle of older people, but they should not just be passive informants but should be active partners in the technology design, development, and delivery process $[63,64]$.

A vast number of applications aimed at older users however focus on gathering data and monitoring the activities of the person to notify the caregivers. Examples include smart family portraits that embed sensors capable of gathering the older person movements [65] and data loggers to be placed in the beds, rooms, and appliances in order to detect early decline for health care intervention [66].

In these types of systems, health care providers are keen on determining patterns of decline [67] and older adults expressed interest of receiving some form of feedback from the system [68]. However, what the technology provides is often more in line with what family, friends, and health care professionals want. While one goal is to allow older people to be safe in their house, older people also want to be able to protect their habits and routines [2] and maintain social relationships outside the home [69].

3.5. Disruption of Routines and Habits. Daily routines and social connections are key to allow older adults to stay active and maintain social interactions with enhanced quality of life [70]. They maintain the same activities, routines, and relationships by developing strategies based on their past experiences [71] to continue to have meaningful relationships and retain their autonomy [44].

In the need for independence, older adults configure and reconfigure their world, but they rely on their own temporal structures such as routines to manage this independence; in turn peace of mind can result from having a routine in place, knowing that things are as usual and that everyone is doing well $[54,72]$.

Routines and habits come with objects or important items that support independence and agency and even connection to friends and services [4]. Objects as simple as a collection of spice jars can be the enablers of important routines [73]: they show the changes that happened over the years as the cooking preference, the apartment, and the circumstances of its owner changed and form an important aspect of the older person's routine. These practices give meaning to people's lives and keep them functional [2] and they are cues that everything is in order [54].

There is clear evidence that older adults value their personal preferences, rhythms, and routines [2, 4]. For example, López Gómez [2] discussed arrangements that older people came up with in order to accommodate a personal emergency care pendant in their autonomous life. The study found how people managed many different workarounds to avoid the stigma or simply the inconvenience of wearing 


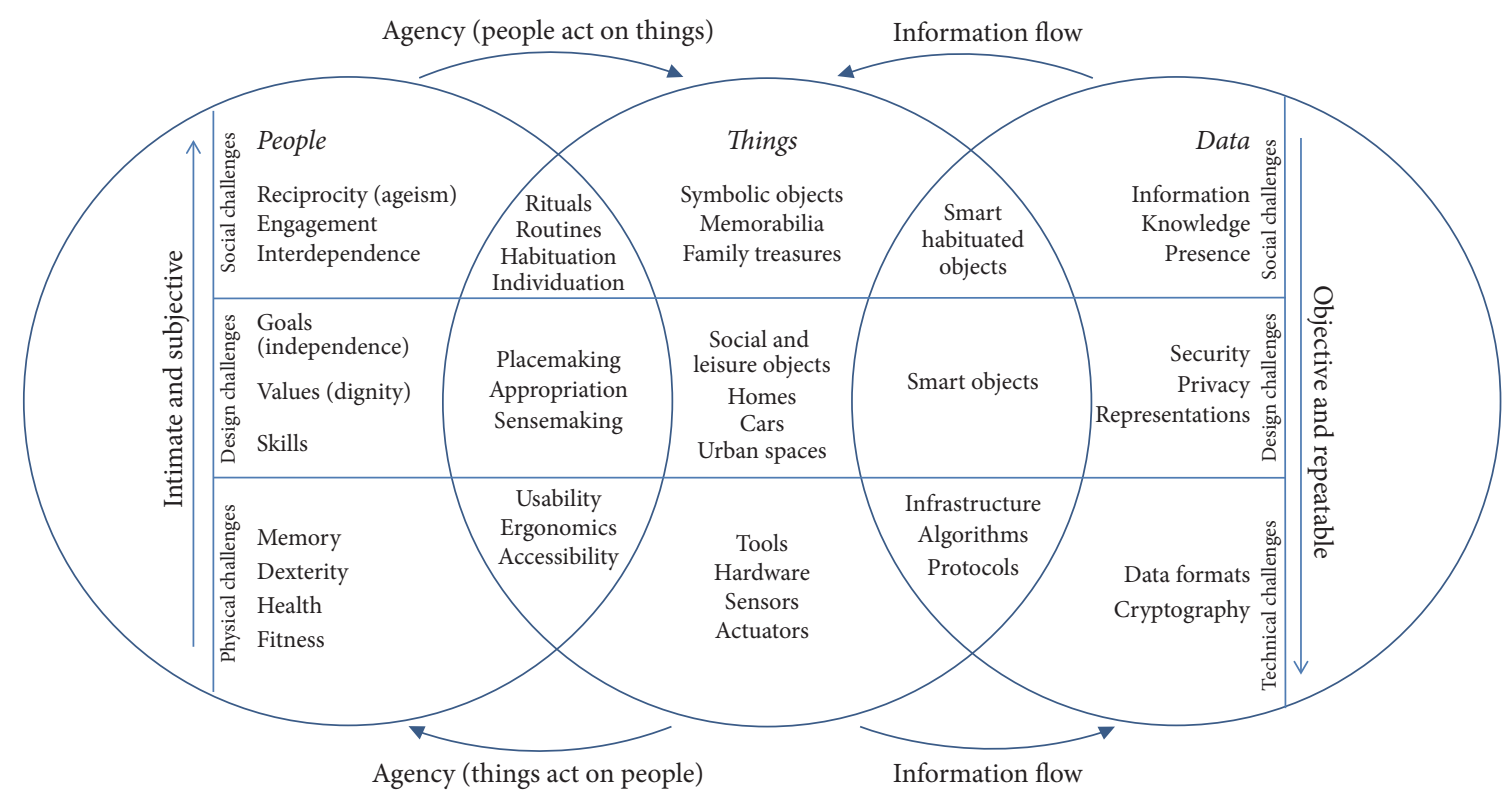

FIgURE 3: An extended framework for the IoT that gathers social and technological perspectives on people, things, and data.

the pendant: hanging it up on a crucifix beside the bedside or wearing it disguised as a brooch. Rather than simply wearing the pendant around their neck, the inventive ways the owners accommodated the pendant show that the device is cumbersome, intrusive, and, in some degree, demeaning.

Similarly, Brereton [4] discussed the habits of an older woman in relation to her objects, noting that each object fits a specific routine that in turn was established and sustained over the years to accommodate the person's capacities and preferences, but also the organization of the home.

3.6. Summary. As we have discussed in the sections above, a technology-driven IoT can potentially miss many opportunities for creating technologies that stimulate, engage, and support older people in their everyday quest for a healthy lifestyle, meaningful relations, and positive ageing.

Much current research conceptualizes ageing in terms of negative changes affecting the mind and body, from loss of memory to fragility, weakness, and disease. Aspirations, ambitions, and personal goals all contribute to make life worth living but are often left out of the picture. The resulting designs, operating under an assumption of providing care in the home to avoid the costs of hospitalization, often result in products that establish an inherently asymmetric relation between the caregivers and the patient, the watchmen, and the person under surveillance.

Sensors and algorithm are often opaque to users and understandably draw some suspicion. The problem of "privacy" is often reduced to a more manageable matter of "confidentiality" depriving in practice the users of the possibility of setting boundaries by deciding what aspects of their life they want to share, for what purposes, and who with. Many designs thrive on the dependency and on the feeling of incompetence of their users: the usefulness of these technologies is often predicated on their users becoming more and more dependent on them, rather than on empowering users giving them control over the system and their own life.

Finally, the routines, habits, and personal objects through which people manage their everyday and enact agency are often neglected. People value their routines both for the purpose they serve and for the sense of accomplishment that comes with being able to arrange one's life and home their own way. These routines, habits, and arrangements are easily disrupted by introducing a new technology and the new practices that come with it. But routines are also important from a system design perspective, because actions and activities are embedded in daily life, and making sense of the activities can hardly be abstracted from the routines, and from the objects and locales in which they take place.

The next section presents an extended framework that represents the IoT paradigm in terms of its broader technical, design, and social challenges. With it we aim to foreground research directions and opportunities that are receiving currently relatively less attention, but also to highlight the necessity of addressing these challenges holistically, rather than as separate research agendas.

\section{An Extended Framework for the Internet of Things}

Our proposed framework, schematized in Figure 3, partly retraces the representation of the IoT paradigm as presented by Atzori and colleagues [7] and extended by Koreshoff et al. [23] and Soro et al. [6]. Rather than conceptualizing the IoT as a convergence of three technology-driven "visions," we acknowledge the key role of "things," but we do so from a human-centered perspective. We argue that what sets the IoT apart from other information and communication technologies is the central role played by things, and how things will facilitate embodied interaction with data and act 
as mediators between people and data and between people and people.

In spite of their central role, things are not the only actors in an IoT scenario, however, and we propose that an IoT application can be fully understood only through a comprehensive analysis of the things, as well as the people and the data, and through a detailed description of how these interact with one another. We will discuss these themes moving bottom up through the framework.

4.1. Understanding People. We certainly cannot attempt here a discussion of how people interact with technology and with one another and why they behave as they do. Nevertheless, it should be clear that describing people only in terms of their physical abilities (or disabilities) would be equivalent to reduce individuals to the measurable properties of their naked bodies. Such dehumanized descriptions would have the same thickness of the stick men of UML diagrams.

One common reason why people fail to adopt new technologies or abandon these technologies short after an initial adoption is that many designs overlook personal motivations, individual goals and values, or propose technologies that do not valorize existing skills or that fail to encourage people to learn new ones [74].

People have their own goals, and being safe in their home is only one of the goals that older people face in their every day. Technologies should be designed so as to support these personal goals and values, not in competition with them. Even when designing with the goal of "assisting" the possible drawbacks in terms of loss of dignity, sense of self-sufficiency, and increased dependency should be scrutinized, and the overall benefit of technologies is discussed in this broader light.

The framework also underlines that people (even users) cannot be considered in isolation. Humans thrive when socially engaged and decline when isolated. Social engagement and reciprocity, people looking after and caring for people, and receiving love and care in return are the best way of ageing healthily. This does not mean that human care is the only possible health care and that IoT tools and services have no role in it. As we have discussed, such simplistic reading fails to account for the care and value that people place on objects $[75,76]$. At the same time, we cannot overlook that people live in a relation of interdependence with one another and with technology. Tools and services designed without enough consideration of these existing networks of relations incur the risk to further marginalize those same people that they aimed to support [77].

4.2. Understanding Things. What are the "things" in the IoT? Papers that discuss the architectural elements of the IoT (protocols, middleware, and addressing) often leave this question intentionally unanswered: a "thing" is any object to which a unique identifier, for example, RFID, can be assigned [7].

There is great power in decoupling the IoT middleware (and the problems of routing, discovery, sensor fusion, authentication, and so on) from the actual objects that the humans will see and use. However, this also hides the enormous complexity that is inherent in "things," in how things relate to particular places, and in how people relate to all of the above.

A majority of studies focus on the home as a preferred setting for IoT applications. This is not to say that the IoT has no place out of the home or that studies that look beyond the home (for example, towards connected vehicles, smart cities, and more [78]) are not available. This may somewhat be limiting the scope of mainstream IoT research, and for this reason the framework includes explicit reference to other application settings, such as the car and the urban space.

Yet, the home as a setting helps to bring into focus important aspects of dignity, privacy, and the importance of routines that in other scenarios may be less evident. Embedding the same technology (more or less) in different everyday objects, for example, a kettle [31], a candle burner [79], a cooking apron [80], makes a big difference, because these objects are used in different contexts, to enable different experiences and sustain different rituals.

Besides their purely functional properties of tools or decorations, people value things and objects for what they afford, what they represent, and the time and effort put in integrating those objects into their home, routines, and habits. These "invisible connections" [3] are of particular value for older people, and new tools that disrupt the comfort given by the existing ones and the habits they sustain can have a hard time being accepted.

For example, designs that aim at creating smart homes cannot overlook that the home is at the core of the older person's emotional well-being [81]. Similarly, smart transport systems cannot be conceptualized without considering that the car, for older people, is a symbol of self-sufficiency, whereas a dependency on others for transportation raises feelings of inadequacy [3]. Objects that have been a companion for many years are difficult to replace, even if the newer model offers augmentations that can support a healthy lifestyle.

Finally, although in the IoT virtually any object can be connected to the network, there are objects that are better left alone, since their value for one person transcends the nature of the object itself. Family jewels, object that represent the connection to a loved one, and objects that came to be part of one person's self-identity are examples of objects that are very problematic to "augment" with technology. For example Leonardi and colleagues noted that some rooms of older people's homes are too "intimate" and unsuited for technologies such as fall detectors [81].

4.3. People and Things. Physical skills and how they match (or not) a given task and a certain technological tool are the focus of "classic" HCI disciplines, such as usability [82] and accessibility [83]. While these disciplines capture important aspects of how technology is used, more recent HCI scholarship acknowledges that the broader "user experience" can hardly be understood only in terms of fitness for purpose and ease of use [84].

We have illustrated how IoT tools and services evoke mixed feelings among potential users. There is evidence that older people react positively to IoT scenarios $[85,86]$, 
but when invited to evaluate the use (i.e., looking beyond the mere usefulness) of particular technologies, for example smart fridge [87], emergency pendants [2], and medication reminders [88], attitudes become more suspicious if not plain hostile.

The study of technology acceptance has been largely limited to the context of the workplace [89] and to a limited extent in the context of leisure and entertainment [90]. Yet, theories of appropriation [74], place-making [91], and design after design [92] can account for the process through which new technologies are inspected, adopted or rejected, possibly modified, and embraced. IoT tools and services will not exist in a vacuum but will, if adopted, become part of ecology of tools and gadgets. Interoperability with these other tools will be crucial, of course. But other subtle factors will play a role as well. Every new tool will require "space," both physical (e.g., a place on the kitchen bench and a power socket to connect), mental (as new skills will have to be acquired to use the tool), and logistical (because other tools will be repurposed or abandoned, routines will be modified, and habits will change).

As users invest time and effort in learning to use a new technology, adapting it to their own needs and routines, the new tool becomes part of people's everyday life and will hardly be abandoned or replaced [93]. As described by Ambe et al. [1], through continuing use or personalization particular technologies can become part of their users' identity (imagine Cartier-Bresson without his Leica), a phenomenon that they dubbed "individuation."

A key aspect, often overlooked in technology-driven designs, is that users will appropriate (in the sense of continuing design in use) the technology they adopt, regardless of the preferences of the designers. Sometimes these adaptations will be so radical that the original purpose of the device may be compromised, as in the example discussed by López Gómez [2] of users hanging their emergency pendants to a crucifix. The lesson is that once a technology is adopted, habituation, appropriation, and individuation will happen. They could work in favour or against the intended functionality, depending on what users value most, so designers and researchers should always keep these phenomena in mind.

4.4. Understanding Data. While there is agreement over the fact that IoT services will gather a great amount of data, the problem of what to do with it has, once again, been approached mostly from a technological perspective. There is great emphasis on the problem of how the things will make sense of the data, from collection to storage, compression, transmission, analysis, fusion, mining, and semantic inferences (see, e.g., [18]). There is currently less emphasis on the complementary and equally important problem of how people will make sense of the data.

While the confidentiality of data can be ensured algorithmically, through authentication and encryption, supporting privacy and security involves creating tools that support users in making informed decisions about their data and systems that are transparent and legible to their users.

For example, what are the implications of sharing physiological data gathered through activity trackers? Wat are the relative risks of storing them in the cloud rather than on a personal device? Who can materially access the data? What can be potentially inferred from it besides the original intent that the data was gathered for? These questions are still very open and can hardly be addressed from a purely technological perspective.

The well-known distinction between data, information, knowledge, and wisdom [94] resonates very well with the issues exposed here. Data, as Ackoff suggests, are plain symbols that need processing to be useful. Automatic systems can aggregate data into information, therefore providing answers to "who," "what," "where," and "when" questions. Knowledge is information in action; it can support "how to" questions. Wisdom is knowledge evaluated and can support reflection and "why" questions. Ackoff said that "it may well be that wisdom-which is essential for the pursuit of ideals or ultimately valued ends-is the characteristic that differentiates man from machines" [94].

4.5. Things and Data. In the IoT, the convergence of things and data produces an ecology of interconnected smart objects [95] that brings interaction out of computer screens and into the real world. From this perspective, the IoT is continuing the research efforts of related fields, such as TUIs $[12,13]$, UbiComp [9], and embodied interaction [96].

Objects and environment can host sensors, networking, and computational capabilities and become aware of the actions, needs, and preferences of their inhabitants or users, but this is only one initial step. The great challenge of the IoT is to bring things and data together in a new type of entity that is greater than the sum of its parts.

Not all technologies are capable of doing this, and in fact they can have the exact opposite effect. Ease of access to information does not necessarily support reflection and deeper thinking [97]. From drivers following meekly their GPS [98] to parents fostering their own anxieties by tracking every breath of their children [99], many "smart" technologies have the potential to deskill and disempower their users.

On the other hand, research projects that have explored smart objects have shown interesting examples in this domain. Fridge doors and mantelpiece clocks can become interactive interconnected devices that support shared awareness and enhance communication in the family [100]. Here meaning is created by the users of the smart objects through unique and personalized arrangements that respect and even enhance, rather than disrupting, existing social relations. The smartness of these smart objects consists in making their users smarter [101].

A powerful opportunity consists in leveraging those objects that, for their very nature, support and shape activities that engage and bring people together [92]. By enhancing routines [4] and rituals [102], IoT tools and services can foster healthy living in powerful and engaging ways. This is particularly relevant for older users, because routines are seen by them as contributing to give purpose to their lives $[2,103]$.

4.6. Operationalizing the Framework. Finally, we offer here a discussion of how the framework can be used, where it fits in the design process, and what gaps, not just in 
knowledge but in also practice, it aims to fill. Conceptually the framework aims to build a bridge between the technical perspectives on IoT design for healthy ageing that are mainly problem driven and oriented towards assisted living and the human perspectives that focus on personal values and aim at supporting healthy ageing through engagement.

Operationally, we invite readers to see the framework as a map of the IoT for healthy ageing design space. This map lays out key research topics, showing how the technical and human perspectives tent to foreground certain research questions and to push other ones to the background.

Looking at this design space from a technical perspective is to navigate the framework from the bottom up. Here we found the layer of physical and technical challenges, people can be described in terms of their capabilities and needs, things are largely considered tools politically and emotionally neutral and can be designed to adapt to these capabilities, and data is defined by specific data formats, including encodings and cryptography. Problems at this level are made tractable by means of abstractions, people are reduced to the data that represent them, and human behavior is schematized and compared against norms, so that sensors and algorithms can decide what falls within normality and what does not and possibly trigger an alarm or act. A key aspect is that, at this end of the design space, agency is with the tools they act on people (and people react, e.g., to smoke detectors, collision alerts, and home surveillance systems). The information flow is largely directed from the people to the data cloud, with plenty of sensors gathering fine grained information that is then processed and assembled within the system.

One level up the framework accounts for growing social and emotional valence, intimacy, and subjectivity. This is the level where design challenges are spelled out. People have goals, skills, and preferences. Their interactions with things are better understood in terms of place-making and appropriation. Making sense of the tools and making sense of the data that can be accessed through the tools becomes a primary concern. At this level things are described also in terms of their social and emotional valence and what they afford in terms of lifestyle, expressions, and social recognition. These objects have a life of their own, and by interfacing with data they can open up possibilities for new and exciting forms of interaction. Security and privacy at this level are also better understood as design problems, as they involve not just the adoption of secure corms of encryption, but also the consistent use and maintenance of safety measures, as well as the ability to decide what to share, who with, and for how long.

Looking at the framework from the top down is to take a human centric perspective that deals with designing for and with individuals and communities and for and with very subjective and intimate goals in mind. At this level, people are better understood in terms of their goals for social engagement, dignity, reciprocity, and respect. To understand their interactions with things, their routines, habits, and social identity need to be understood in addition to purely utilitarian values. Objects are better described also in terms of their subjective value, such as in the case of family memorabilia, or symbolic objects, that come to represent loved ones, or are seen as representing our identity in relation to others. Smart objects at this level become unique and sometimes irreplaceable. Augmenting existing objects may not be feasible, as it may compromise the original object. Some objects that have particular meaning or personal value may be better left alone. Technologies at this level are better understood in terms of the social relations that they can facilitate (or compromise) and the personal attachment to specific objects and routines. Here agency is with the people: they use the tools and service to engage and interact with others in their own terms. The information flow is largely from the cloud to the users, as they explicitly interact with the IoT to communicate and collaborate.

It is important to note here that neither of the two perspectives, technical and human, can stand on its own, which is why we offer this framework in the first place, to help to get a glance of the bigger picture. Like with De Bono's metaphorical "thinking hats," it is sometimes helpful to force ourselves out of our comfort zone to take a different perspective. It also helps to understand the limits and the pitfalls of each. Moving from a technical perspective, a refusal to adopt technologies that are useful and reliable may seem irrational and stubborn. Moving from a human perspective one may be tempted to trust that specific "technical" problems, for example, latency and security, will eventually be addressed and should not be a concern.

Finally, we intentionally avoided to discuss the methods that support research at each perspective, as this would have required a space well beyond this paper. However, the framework touches on the fact that the two perspectives rest often on very different epistemological stances. Moving up the framework, the research problems become focused more on personal perceptions, needs, and feelings and it should be no surprise that the research approaches become more qualitative, and the credibility of the research findings is based on the abundance of background and details in the accounts offered. Similarly, navigating down the framework, goals and problems are generalised into models that can be studied and validated with quantitative approaches, if not through pure mathematical proof. We point the reader elsewhere (for example, Venkatesh and colleagues [104] or Matthews and Brereton [105]) for a discussion of these matters. We wish to note here, however, that these differences in research approach are signs of different worldviews that the proposed framework seeks to make more visible.

4.7. Limitations. Having discussed the values and goals that could inform the design of IoT technologies for healthy living, we need to point out here how the framework, while sketching a "bigger picture," is still constrained to a design orientation that can potentially reinscribe the same technology-centrism for which we set out to offer a counterpoint.

One first limitation is that many key themes highlighted in the framework are derived from studies that are situated (spatially, temporally, and culturally) in a very specific context. So for example, noting that depending upon others for transport creates feelings of inadequacy [3] subsumes a specific cultural reference that values independence (as 
opposite to interdependence, see, e.g., [106]) and associates it to owning a car and driving it personally. This may represent a correct assumption where/when the study was conducted but may, and in general will, change in the future or elsewhere.

Morozov [107] coined the term "technological solutionism" to characterize a tendency to approach complex problems with deep social, economic, and ethical implications, as purely technical, and offer a "solution" for them. Technological solutionism prospers in technocentric and technooptimist ground. Maturo [108] noted how a solutionist standpoint pervades much discourse around monitoring and health application: "quantification and solutionism implicitly deny the fundamental role of social factors for individual health. One of the few certainties of sociology of health and epidemiology is the strong correlation between social determinants and health" [108].

Suchman [109] presented the complicated and usually opposing views on the visions of care by the government and by different organizations (e.g., technology industry and medical field) with the experiences and realities in the perspective of the receiver of care. Suchman highlights how information systems in healthcare settings are often ambitious and envisions a utopian setup that falls short because local practice of care and knowledge on how to improve it were not considered [109].

Henwood and colleagues noted that healthy living is a difficult process involving emotional challenges, anxiety, and uncertainties that interdependence with others who have similar experiences in conjunction with the kindness of service providers can help to support [110]. Mol [111] further highlighted that care is best understood and practiced when it is considered as a shared involvement among health care providers, family, and friends as well as technologies and other actors.

It is reasonable to extend similar considerations to healthy ageing and stay alert to the risk of responding to a stereotyped vision of ageing with an idealistic vision of an IoT that puts social engagement and healthy ageing within reach of a click. Such utopian vision could ironically have the concrete effect of presenting healthy ageing as a matter of individual choice, shifting responsibility towards the older people, and away from the community, the institutions, and the service providers.

There is a clear need to broaden the scope of IoT research even more than proposed here, to better account for the (sometimes competing) goals of institutions and industry, for the changing culture among users as today's adults grow older, and from the increasing challenges of improving our lifestyle together with our lifespan.

\section{Conclusion}

In the introductory sections to this paper we have provided some examples of widely referenced papers that depicted older people as fragile, in constant need of care and medical attention, and passive subjects of "smart" sensing technologies. Those papers resulted from a Google scholar query on "Internet of Things and elderly." Curiously, the analogous query for "Internet of Things and older adults" gives a completely different picture of the current IoT research, one that includes some of the literature that we have proposed as counterexamples, such as $[3,29]$.

There are two distinct bodies of literature on the Internet of Things that are pursuing the same goals from different directions and even using different languages. One derives from a technical perspective while the other comes from a human perspective. From a technical perspective, sensors can automatically detect physical activity, thus enabling older people to live independently, while sensors in essence check that they are active, remind them to take their pills, and so on. From a human perspective, people seek control over their lives, good health, social connection, and a sense of wellbeing that comes from having purpose and feeling competent in daily routines.

We have proposed a framework that aims at bridging these two perspectives, gathering into a coherent picture the main themes avenues for research. William Buxton, a pioneer of multitouch and manipulative interaction, noted that 30 years between seminal research and commercial success are not at all unusual in the world of computing [112]. The technologies we are studying today are the same ones that will be imposed on us in the future by our apprehensive children and a financially exhausted health care department.

Will these technologies be an enabler of independence and control or will they undermine it, making older people feel subjects of surveillance and incompetent? And is there a middle path that we might take in design that creates innovative technologies that are aesthetic in form and function and empowering to use?

\section{Conflicts of Interest}

The authors declare that there are no conflicts of interest regarding the publication of this article.

\section{Acknowledgments}

This work was partially funded by Australian Research Council, Grant DP150104001.

\section{References}

[1] A. H. Ambe, M. Brereton, A. Soro, and P. Roe, “Technology Individuation," in Proceedings of the the 2017 CHI Conference, pp. 6632-6644, Denver, Colorado, USA, May 2017.

[2] D. López Gómez, "Little arrangements that matter. Rethinking autonomy-enabling innovations for later life," Technological Forecasting \& Social Change, vol. 93, pp. 91-101, 2015.

[3] K. Vaisutis, M. Brereton, T. Robertson et al., "Invisible connections: Investigating older people's emotions and social relations around objects," in Proceedings of the 32nd Annual ACM Conference on Human Factors in Computing Systems, CHI 2014, pp. 1937-1940, can, May 2014.

[4] M. Brereton, "Habituated objects: Everyday tangibles that foster the independent living of an elderly woman," Interactions, vol. 20 , no. 4 , pp. $20-24,2013$.

[5] K. Ashton, "That 'internet of things' thing," RFID Journal, vol. 22, no. 7, pp. 97-114, 2009. 
[6] A. Soro, M. Brereton, and P. Roe, “The Messaging Kettle: It's IoTea time," Aarhus Series on Human Centered Computing, vol. 1, no. 1, p. 2, 2015.

[7] L. Atzori, A. Iera, and G. Morabito, "The internet of things: a survey," Computer Networks, vol. 54, no. 15, pp. 2787-2805, 2010.

[8] M. Weiser, R. Gold, and J. S. Brown, "Origins of ubiquitous computing research at PARC in the late 1980s," IBM Systems Journal, vol. 38, no. 4, pp. 693-695, 1999.

[9] M. Weiser, "Ubiquitous computing," The Computer Journal, vol. 26, no. 10, pp. 71-72, 1993.

[10] M. Weiser and J. Seely Brown, "The coming age of calm technology. In Beyond calculation: The next fifty years of computing," in Mark Weiser and John Seely Brown, P. J. Denning and R. M. Metcalfe, Eds., pp. 75-86, Copernicus - SpringerVerlag, New York, NY, USA, 1997.

[11] M. Weiser, "The computer for the 21st century," ACM SIGMOBILE Mobile Computing and Communications Review, vol. 3, no. 3, pp. 3-11, 1999.

[12] H. Ishii, “Tangible bits: Beyond pixels," in Proceedings of the 2nd International Conference on Tangible and Embedded Interaction, TEI 2008, pp. xv-xxv, deu, February 2008.

[13] H. Ishii and B. Ullmer, "Tangible bits," in Proceedings of the the SIGCHI conference, pp. 234-241, Atlanta, Georgia, United States, March 1997.

[14] E. Aarts and R. Wichert, "Ambient intelligence," in Technology Guide, pp. 244-249, Springer, Berlin Heidelberg, Germany, 2009.

[15] G. D. Abowd, A. K. Dey, P. J. Brown, N. Davies, M. Smith, and P. Steggles, "Towards a better understanding of context and context-awareness," in Handheld and Ubiquitous Computing: First International Symposium, HUC '99 Karlsruhe, Germany, September 27-29, 1999 Proceedings, vol. 1707 of Lecture Notes in Computer Science, pp. 304-307, Springer, Berlin, Germany, 1999.

[16] S. Mann, "Wearable computing: a first step toward personal imaging," The Computer Journal, vol. 30, no. 2, pp. 25-32, 1997.

[17] T. Starner, S. Mann, B. Rhodes et al., "Augmented reality through wearable computing," Presence: Teleoperators and Virtual Environments, vol. 6, no. 4, pp. 386-398, 1997.

[18] J. Gubbi, R. Buyya, S. Marusic, and M. Palaniswami, "Internet of Things (IoT): a vision, architectural elements, and future directions," Future Generation Computer Systems, vol. 29, no. 7, pp. 1645-1660, 2013.

[19] C. Perera, A. Zaslavsky, P. Christen, and D. Georgakopoulos, "Sensing as a service model for smart cities supported by internet of things," Transactions on Emerging Telecommunications Technologies, vol. 25, no. 1, pp. 81-93, 2014.

[20] F. Mattern and C. Floerkemeier, "From the internet of computers to the Internet of Things," in From Active Data Management to Event-Based Systems and More, vol. 6462 of Lecture Notes in Computer Science, pp. 242-259, Springer, Berlin, Germany, 2010.

[21] M. Swan, "Sensor mania! The internet of things, wearable computing, objective metrics, and the quantified self 2.0," Journal of Sensor and Actuator Networks, vol. 1, no. 3, pp. 217253, 2012.

[22] D. Miorandi, S. Sicari, F. de Pellegrini, and I. Chlamtac, "Internet of things: vision, applications and research challenges," Ad Hoc Networks, vol. 10, no. 7, pp. 1497-1516, 2012.

[23] T. L. Koreshoff, T. W. Leong, and T. Robertson, "Approaching a human-centred internet of things," in Proceedings of the 25th
Australian Computer-Human Interaction Conference: Augmentation, Application, Innovation, Collaboration, OzCHI 2013, pp. 363-366, aus, November 2013.

[24] L. Tan and N. Wang, "Future internet: the internet of things," in Proceedings of the 3rd International Conference on Advanced Computer Theory and Engineering (ICACTE '10), pp. V5376V5380, IEEE, Chengdu, China, August 2010.

[25] J. Durick, T. Robertson, M. Brereton, F. Vetere, and B. Nansen, "Dispelling ageing myths in technology design," in Proceedings of the 25th Australian Computer-Human Interaction Conference: Augmentation, Application, Innovation, Collaboration, $\mathrm{OzCHI}$ 2013, pp. 467-476, aus, November 2013.

[26] A. Zanella, N. Bui, A. P. Castellani, L. Vangelista, and M. Zorzi, "Internet of things for smart cities," IEEE Internet of Things Journal, vol. 1, no. 1, pp. 22-32, 2014.

[27] H. Sundmaeker, P. Guillemin, P. Friess, and S. Woelfflé, Vision and challenges for realising the Internet of Things, Cluster of European Research Projects on the Internet of Things, European Commision, 2010.

[28] A. J. Stankovic, "Research directions for the internet of things," IEEE Internet of Things Journal, vol. 1, no. 1, pp. 3-9, 2014.

[29] T. L. Koreshoff, T. Robertson, and T. W. Leong, "Internet of things: A review of literature and products," in Proceedings of the 25th Australian Computer-Human Interaction Conference: Augmentation, Application, Innovation, Collaboration, $\mathrm{OzCHI}$ 2013, pp. 335-344, aus, November 2013.

[30] B. Nansen, L. Van Ryn, F. Vetere, T. Robertson, M. Brereton, and P. Douish, "An internet of social things," in Proceedings of the 26th Australian Computer-Human Interaction Conference, OzCHI 2014, pp. 87-96, aus, December 2014.

[31] M. Brereton, A. Soro, K. Vaisutis, and P. Roe, “The messaging kettle: Prototyping connection over a distance between adult children and older parents," in Proceedings of the 33rd Annual CHI Conference on Human Factors in Computing Systems, CHI 2015, pp. 713-716, kor, April 2015.

[32] S. Nassir, T. W. Leong, and T. Robertson, "Positive Ageing: Elements and factors for design," in Proceedings of the 27th Australian Computer-Human Interaction Conference, OzCHI 2015, pp. 264-268, aus, December 2015.

[33] R. L. Bowen and C. S. Atwood, "Living and Dying for Sex," Gerontology, vol. 50, no. 5, pp. 265-290, 2004.

[34] M. Gorman, "Development and the rights of older people," in The ageing and development report. Poverty, independence and the world's older people, J. Randel, T. German, and D. Ewing, Eds., pp. 3-21, Earthscan Publications, London, England, 1999.

[35] C. Kramarae and A. G. Miller, "In the Eye of the Beholder: Contemporary Issues in Stereotyping.", Contemporary Sociology, vol. 12, no. 4, p. 453, 1983.

[36] P. J. Stearns, "Old age family conflict: The perspective of the past," in Elder Abuse: Conflict in The Family, K. A. Pillemer and R. S. Wolf, Eds., pp. 3-24, Auburn House Publishing, Dover, MA, USA, 1986.

[37] T. D. Nelson, "Ageism: prejudice against our feared future self," Journal of Social Issues, vol. 61, no. 2, pp. 207-221, 2005.

[38] G. F. Streib, E. Cumming, W. E. Henry, and T. Parsons, "Growing Old: The Process of Disengagement.," American Sociological Review, vol. 27, no. 4, p. 561, 1962.

[39] United Nations Department of Economic and Social Affairs, World Population Prospects: The 2015 Revision (ESA/P/ WP.241), 2015. 
[40] A. Light, W. Tuck Leong, and T. Robertson, "Ageing well with CSCW", in ECSCW 2015: Proceedings of the 14th European Conference on Computer Supported Cooperative Work, pp. 295304, Oslo , Norway, 2015.

[41] World Health Organization, Active Aging: A Policy Framework, World Health Organization, Geneva, 2002.

[42] E. Giaccardi, S. C. Kuijer, and L. Neven, "Design for resourceful ageing: intervening in the ethics of gerontechnology," in Proceedings of DRS 2016, Design + Research + Society Future-FutureFocused Thinking, 2016.

[43] E. Brandt, T. Binder, L. Malmborg, and T. Sokoler, "Communities of everyday practice and situated elderliness as an approach to co-design for senior interaction," in Proceedings of the the 22nd Conference of the Computer-Human Interaction Special Interest Group of Australia, p. 400, Brisbane, Australia, November 2010.

[44] S. E. Lindley, R. Harper, and A. Sellen, "Designing for elders: Exploring the complexity of relationships in later life," in Proceedings of the 22nd British HCI Group Annual Conference on People and Computers: Culture, Creativity, Interaction, BCS HCI 2008, pp. 77-86, Singapore, September 2008.

[45] J. L. Wiles, A. Leibing, N. Guberman, J. Reeve, and R. E. S. Allen, "The meaning of 'aging in place' to older people," The Gerontologist, vol. 52, no. 3, pp. 357-366, 2012.

[46] G. M. Boulton-Lewis, L. Buys, J. Lovie-Kitchin, K. Barnett, and L. N. David, "Ageing, learning, and computer technology in Australia," Educational Gerontology, vol. 33, no. 3, pp. 253-270, 2007.

[47] J. Austin, H. H. Dodge, T. Riley, P. G. Jacobs, S. Thielke, and J. Kaye, "A Smart-Home System to Unobtrusively and Continuously Assess Loneliness in Older Adults," IEEE Journal of Translational Engineering in Health and Medicine, vol. 4, 2016.

[48] D. Harley and G. Fitzpatrick, "YouTube and intergenerational communication: The case of Geriatric1927," Universal Access in the Information Society, vol. 8, no. 1, pp. 5-20, 2009.

[49] C. Milligan, C. Roberts, and M. Mort, "Telecare and older people: Who cares where?" Social Science \& Medicine, vol. 72, no. 3, pp. 347-354, 2011.

[50] S. Wyche, P. Sengers, and R. E. Grinter, "Historical analysis: Using the past to design the future," Lecture Notes in Computer Science (including subseries Lecture Notes in Artificial Intelligence and Lecture Notes in Bioinformatics): Preface, vol. 4206, pp. 3551, 2006.

[51] J. E. Fischer, A. Crabtree, T. Rodden et al., “"Just whack it on until it gets hot": Working with IoT data in the home," in Proceedings of the 34th Annual Conference on Human Factors in Computing Systems, CHI 2016, pp. 5933-5944, usa, May 2016.

[52] Y. Rogers, "Moving on from Weiser's Vision of Calm Computing: Engaging UbiComp Experiences," in UbiComp 2006: Ubiquitous Computing, vol. 4206 of Lecture Notes in Computer Science, pp. 404-421, Springer Berlin Heidelberg, Berlin, Heidelberg, 2006.

[53] P. Dourish, "What we talk about when we talk about context," Personal and Ubiquitous Computing, vol. 8, no. 1, pp. 19-30, 2004.

[54] J. Birnholtz and M. Jones-Rounds, "Independence and interaction: Understanding seniors' privacy and awareness needs for aging in place," in Proceedings of the 28th Annual CHI Conference on Human Factors in Computing Systems, CHI 2010, pp. 143-152, usa, April 2010.
[55] V. Claes, E. Devriendt, J. Tournoy, and K. Milisen, "Attitudes and perceptions of adults of 60 years and older towards inhome monitoring of the activities of daily living with contactless sensors: An explorative study," International Journal of Nursing Studies, vol. 52, no. 1, pp. 134-148, 2015.

[56] L. Dupuy, C. Consel, and H. Sauzéon, "Self determinationbased design to achieve acceptance of assisted living technologies for older adults," Computers in Human Behavior, vol. 65, pp. 508-521, 2016.

[57] G. Newe, "Delivering the Internet of Things," Network Security, vol. 2015, no. 3, pp. 18-20, 2015.

[58] R. Want, B. N. Schilit, and S. Jenson, "Enabling the internet of things," The Computer Journal, vol. 48, no. 1, pp. 28-35, 2015.

[59] J. F. Coughlin, L. Jasmin, L. A. D’Ambrosio, and B. Reimer, "Adult childrens perceptions of intelligent home systems in the care of elderly parents," in Proceedings of the 3rd International Convention on Rehabilitation Engineering \& Assistive Technology, ACM, 2009.

[60] E. Grönvall and N. Verdezoto, "Beyond self-monitoring: Understanding non-functional aspects of home-based healthcare technology," in Proceedings of the 2013 ACM International Joint Conference on Pervasive and Ubiquitous Computing, UbiComp 2013, pp. 587-596, che, September 2013.

[61] F. Nunes, N. Verdezoto, G. Fitzpatrick, M. Kyng, E. Grönvall, and C. Storni, "Self-care technologies in HCI: Trends, tensions, and opportunities," ACM Transactions on Computer-Human Interactions (TOCHI), vol. 22, no. 6, article no. 33, 2015.

[62] C. Sas, K. Brahney, C. Oechsner et al., "Communication Needs of Elderly at Risk of Falls and their Remote Family," in Proceedings of the the 2017 CHI Conference Extended Abstracts, pp. 2900-2908, Denver, Colorado, USA, May 2017.

[63] G. Graffigna, S. Barello, B. K. Wiederhold, A. C. Bosio, and G. Riva, "Positive technology as a driver for health engagement," Studies in Health Technology and Informatics, pp. 9-17.

[64] B. Nansen, F. Vetere, T. Robertson, J. Downs, M. Brereton, and J. Durick, "Reciprocal habituation: a study of older people and the Kinect," ACM Transactions on Computer-Human Interactions (TOCHI), vol. 21, no. 3, article 18, 20 pages, 2014.

[65] J. Rowan and E. D. Mynatt, "Digital Family Portrait Field Trial," in Proceedings of the the SIGCHI conference, p. 521, Portland, Oregon, USA, April 2005.

[66] J. Marilyn, Marjorie S., S. Miller, and J. Krampe, "Using Technology to Enhance Aging in Place," in International Conference On Smart homes and health Telematics, pp. 169-176, 2008.

[67] M. L. Lee and A. K. Dey, "Sensor-based observations of daily living for aging in place," Personal and Ubiquitous Computing, vol. 19, no. 1, pp. 27-43, 2015.

[68] J. Doyle, N. Caprani, and R. Bond, “Older adults' attitudes to self-management of health and wellness through smart home data," in Proceedings of the 9th International Conference on Pervasive Computing Technologies for Healthcare, PervasiveHealth 2015, pp. 129-136, tur, May 2015.

[69] J. C. Aceros, J. Pols, and M. Domènech, "Where is grandma? Home telecare, good aging and the domestication of later life," Technological Forecasting \& Social Change, vol. 93, pp. 102-111, 2015.

[70] R. C. Atchley, "Activity theory," in The Encyclopedia of Aging, Springer Publishing, 4th edition, 2006.

[71] R. C. Atchley, "A Continuity Theory of Normal Aging," The Gerontologist, vol. 29, no. 2, pp. 183-190, 1989.

[72] G. de Moustier, “The story of odile," Gratiane de Moustier, 2008. 
[73] A. Costall and O. Dreir, Eds., Doing Things with Things: The Design and Use of Everyday Objects, Ashgate Publishing, Aldershot, England, 2006.

[74] J. Carroll, Completing Design in Use: Closing the Appropriation Cycle, European Conference of Information Systems, January 2004, http://aisel.aisnet.org/ecis2004.

[75] B. Friedman, P. H. Kahn, and J. Hagman, "Hardware companions?" in Proceedings of the the conference, p. 273, Ft. Lauderdale, Florida, USA, April 2003.

[76] J. Pols and I. Moser, "Cold technologies versus warm care? On affective and social relations with and through care technologies," Alter, vol. 3, no. 2, pp. 159-178, 2009.

[77] A. Light, "Digital interdependence and how to design for it," Interactions, vol. 18, no. 2, p. 34, 2011.

[78] F. Bonomi, R. Milito, J. Zhu, and S. Addepalli, "Fog computing and its role in the internet of things," in Proceedings of the 1st ACM Mobile Cloud Computing Workshop, MCC 2012, pp. 13-15, fin, August 2012.

[79] H. Baharin and S. Khalidi, "Fyro: A symbolic-based phatic technology," in Proceedings of the 27th Australian ComputerHuman Interaction Conference, OzCHI 2015, pp. 304-308, aus, December 2015.

[80] M. Z. Chai, A. Soro, P. Roe, and M. Brereton, "Cooking Together at a Distance," in Proceedings of the the 2017 CHI Conference Extended Abstracts, pp. 2437-2444, Denver, Colorado, USA, May 2017.

[81] C. Leonardi, C. Mennecozzi, E. Not et al., "Knocking on elders' door: Investigating the functional and emotional geography of their domestic space," in Proceedings of the 27th International Conference Extended Abstracts on Human Factors in Computing Systems, CHI 2009, pp. 1703-1711, usa, April 2009.

[82] J. Nielsen, Usability Engineering, Elsevier, 1994.

[83] Constantine Stephanidis, User interfaces for all: concepts, methods, and tools, CRC Press, 2000.

[84] A. Dillon, "Beyond usability: Process, outcome, and affect in Human Computer Interactions," Canadian Journal of Information and Library Science, vol. 26, no. 4, pp. 67-69, 2001.

[85] S. Gaul and M. Ziefle, "Smart Home Technologies: Insights into Generation-Specific Acceptance Motives," in HCI and Usability for e-Inclusion, vol. 5889 of Lecture Notes in Computer Science, pp. 312-332, Springer Berlin Heidelberg, Berlin, Heidelberg, 2009.

[86] R. Steele, A. Lo, C. Secombe, and Y. K. Wong, "Elderly persons' perception and acceptance of using wireless sensor networks to assist healthcare," International Journal of Medical Informatics, vol. 78, no. 12, pp. 788-801, 2009.

[87] M. Rothensee, "User Acceptance of the Intelligent Fridge: Empirical Results from a Simulation," in The Internet of Things $S E$ - 8, C. Floerkemeier, L. Marc, F. Elgar et al., Eds., pp. 123-139, Springer Berlin Heidelberg, Heidelberg, Germany, 2008.

[88] K. Renaud and J. Van Biljon, "Predicting technology acceptance and adoption by the elderly: A qualitative study," in Proceedings of the SAICSIT 2008: riding the wave of technology - 2008 Annual Research Conference of the South African Institute of Computer Scientists and Information Technologists, pp. 210-219, zaf, October 2008.

[89] V. Venkatesh, M. G. Morris, G. B. Davis, and F. D. Davis, "User acceptance of information technology: toward a unified view," MIS Quarterly, vol. 27, no. 3, pp. 425-478, 2003.

[90] H. van der Heijden, "User acceptance of hedonic information systems," MIS Quarterly, vol. 28, no. 4, pp. 695-704, 2004.
[91] K. Riemer and R. B. Johnstone, "Place-making: A phenomenological theory of technology appropriation," in Proceedings of the Proc. of 33rd International Conference on Information Systems, 2012, http://aisel.aisnet.org/icis2012/proceedings/ SocialImpacts/5/.

[92] P. Ehn, "DOC and the power of things and representatives," in Proceedings of the the 26th annual ACM international conference, p. 31, Lisbon, Portugal, September 2008.

[93] A. Soro, M. Brereton, and P. Roe, "Towards an analysis framework of technology habituation by older users," in Proceedings of the 11th ACM SIGCHI Conference on Designing Interactive Systems, DIS 2016, pp. 1021-1033, aus, June 2016.

[94] L. R. Ackoff, “From data to wisdom," Journal of applied systems analysis, vol. 16, no. 1, pp. 3-9, 1989.

[95] G. Kortuem, F. Kawsar, V. Sundramoorthy, and D. Fitton, "Smart objects as building blocks for the internet of things," IEEE Internet Computing, vol. 14, no. 1, pp. 44-51, 2010.

[96] P. Dourish, Where the Action Is: The Foundations of Embodied Interaction, MIT Press, 2004, http://mitpress.mit.edu/ books/where-action.

[97] C. Nicholas, "Is Google making us stupid?" Yearbook of the National Society for the Study of Education, vol. 107, no. 2, pp. 89-94, 2008.

[98] G. Leshed, T. Velden, O. Rieger, B. Kot, and P. Sengers, "In-car GPS navigation: Engagement with and disengagement from the environment," in Proceedings of the 26th Annual CHI Conference on Human Factors in Computing Systems, CHI 2008, pp. 16751684, ita, April 2008.

[99] G. Marx and V. Steeves, "From the beginning: Children as subjects and agents of surveillance," Surveillance \& Society, vol. 7, no. 3/4, pp. 192-230, 2010.

[100] A. S. Taylor, R. Harper, L. Swan, S. Izadi, A. Sellen, and M. Perry, "Homes that make us smart," Personal and Ubiquitous Computing, vol. 11, no. 5, pp. 383-393, 2007.

[101] N. Jeremijenko, “A futureproofed power meter," Whole Earth, Summer, 2001.

[102] S. David Kirk, D. Chatting, Y. Paulina, and J. Bichard, "Ritual Machines I \& \#38; II: Making Technology at Home," in Proceedings of the 2016 CHI Conference on Human Factors in Computing Systems, ACM, 2016.

[103] M. Blythe, J. Steane, J. Roe, and C. Oliver, "Solutionism, the game: Design fictions for positive aging," in Proceedings of the $33 r$ Annual CHI Conference on Human Factors in Computing Systems, CHI 2015, pp. 3849-3858, kor, April 2015.

[104] V. Venkatesh, S. A. Brown, and H. Bala, "Bridging the qualitative-quantitative divide: Guidelines for conducting mixed methods research in information systems," MIS Quarterly: Management Information Systems, vol. 37, no. 1, pp. 21-54, 2013.

[105] B. Matthews and M. Brereton, Navigating the methodological mire: practical epistemology in design research, 2015.

[106] J. Henrich, S. J. Heine, and A. Norenzayan, “The weirdest people in the world?" Behavioral and Brain Sciences, vol. 33, no. 2-3, pp. 61-83, 2010.

[107] E. Morozov, To save everything, click here: Technology, solutionism, and the urge to fix problems that don't exist, Penguin UK, 2013.

[108] A. Maturo, "Fatism, self-monitoring and the pursuit of healthiness in the time of technological solutionism," Italian Sociological Review, vol. 4, no. 2, pp. 157-171, 2014. 
[109] L. Suchman, "Sociotechnologies of care: Visions and realities," in Proceedings of the 3rd International Conference on Information Technology in Health Care: Socio-Technical Approaches, ITHC 2007, pp. 1-2, aus, August 2007.

[110] F. Henwood, R. Harris, and S. Philippa, "Informing health? Negotiating the logics of choice and care in everyday practices of, healthy living," Social Science \& Medicine, vol. 72, no. 12, pp. 2026-2032, 2011.

[111] A. Pichelstorfer, "Mol, Annemarie (2008): The Logic of Care: Health and the Problem of Patient Choice, London: Routledge Mol, Annemarie (2008): The Logic of Care: Health and the Problem of Patient Choice, London: Routledge," Culture Unbound: Journal of Current Cultural Research, vol. 4, no. 3, pp. 533-535, 2012.

[112] B. Buxton, “The long nose of innovation," Insight, vol. 11, p. 27, 2008. 


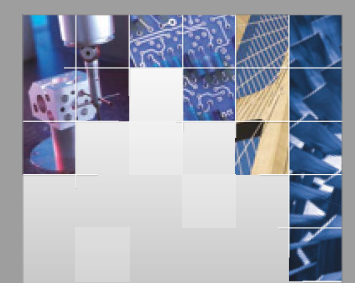

\section{Enfincering}
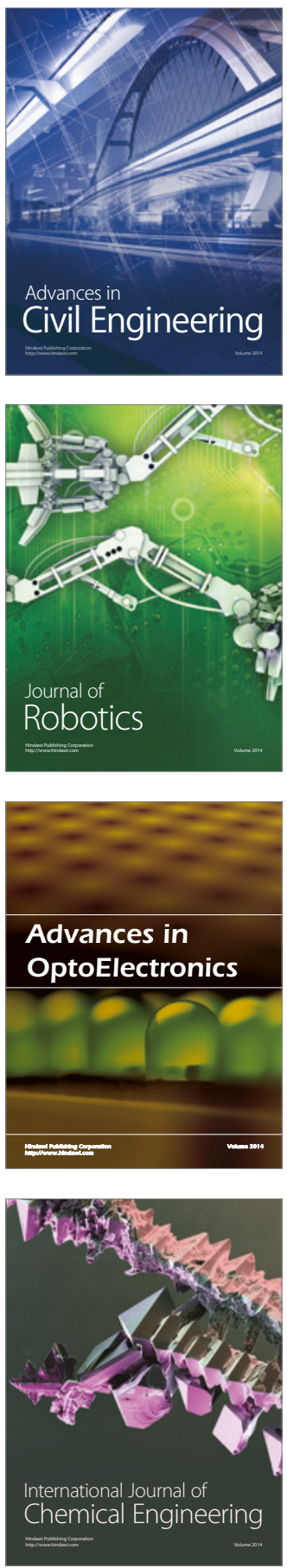

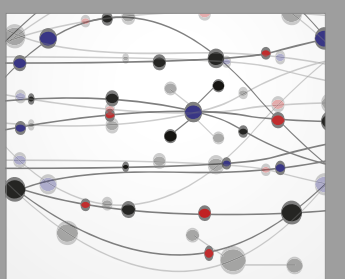

The Scientific World Journal

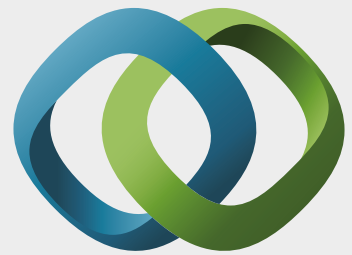

\section{Hindawi}

Submit your manuscripts at

https://www.hindawi.com
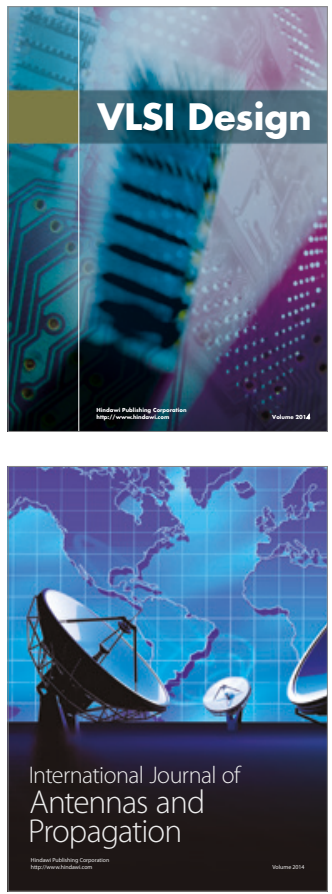

\section{Rotating}

Machinery
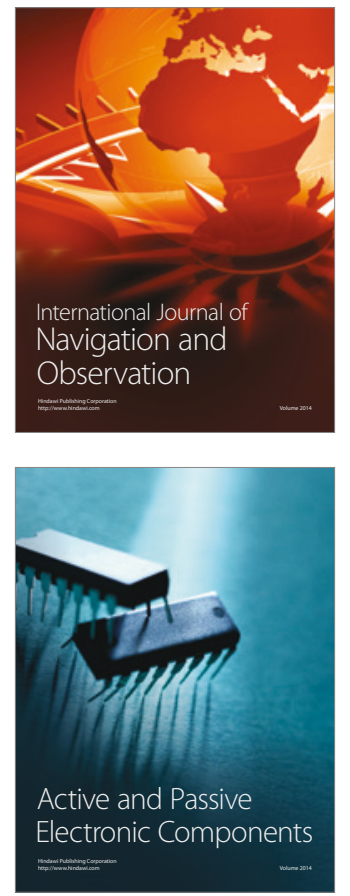
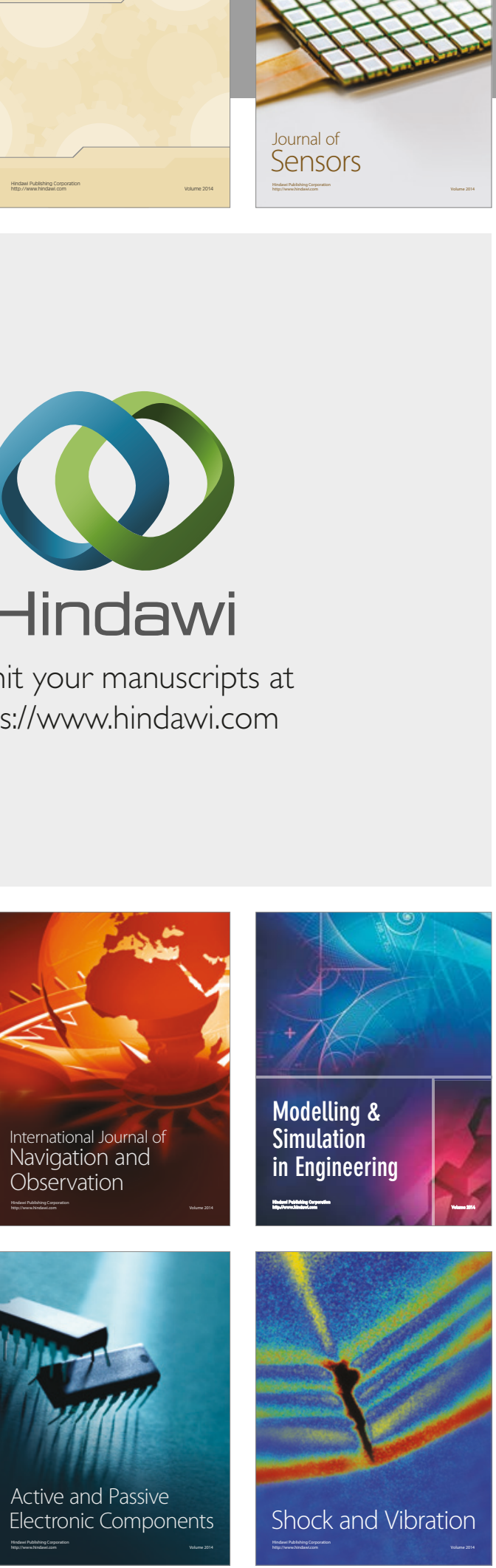
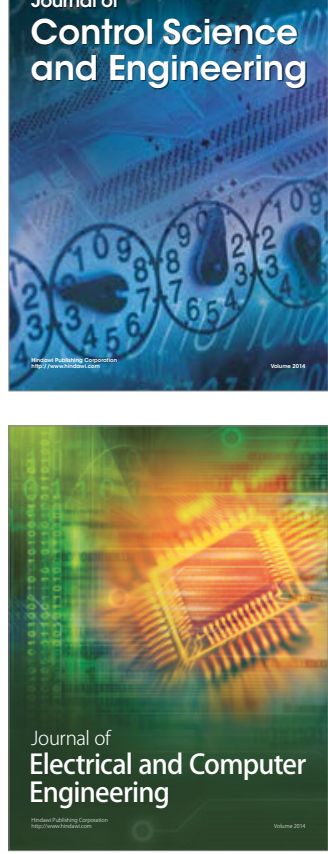

Distributed

Journal of

Control Science

and Engineering
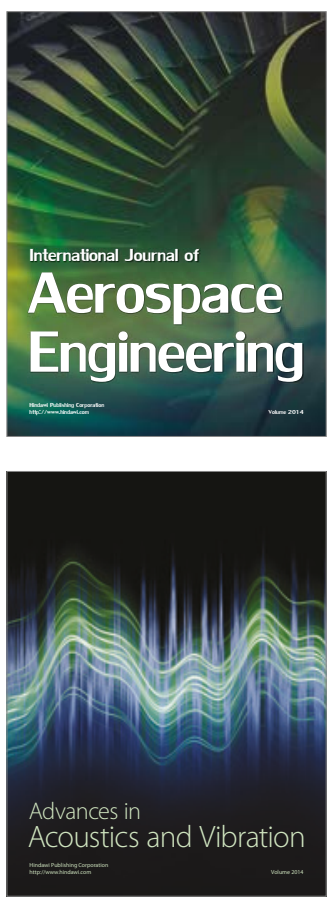

Sensor Networks 